\title{
Association between health literacy and mortality: a systematic review and meta- analysis
}

\author{
Zhao-ya Fan ${ }^{1}$, Yuan Yang $^{2}$ and Fan Zhang ${ }^{1 *}$ (D)
}

\begin{abstract}
Background: To identify the relationship between health literacy $(H L)$ and mortality based on a systematic review and meta-analysis.

Methods: Literature published from database inception until July 2020 was searched using the PubMed and Web of Science databases, using relevant keywords and clear inclusion and exclusion criteria. The search was limited to English language articles. Two reviewers independently selected studies and extracted data. Pooled correlation coefficients and their 95\% confidence intervals (Cl) between $\mathrm{HL}$ and mortality were estimated using Stata 15.0 software. Potential sources of heterogeneity were explored using subgroup analysis, sensitivity analysis, and metaregression. Quality of the original studies that were included in the meta-analysis was evaluated using the Newcastle-Ottawa Scale. A funnel plot and Egger's test were used to determine whether significant publication bias was present.
\end{abstract}

Results: Overall, 19 articles were included, reporting on a total of 41,149 subjects. Eleven were prospective cohort studies, and all articles were considered "good" quality. The most used screening instruments were the short Test of Functional Health Literacy (S-TOFHLA) in Adults and the Brief Health Literacy Screen (BHLS). Among 39,423 subjects (two articles did not report the number of patients with low HL), approximately 9202 (23\%) had inadequate or marginal $\mathrm{HL}$. The correlation coefficient between $\mathrm{HL}$ and mortality was $1.25(95 \% \mathrm{Cl}=0.25-0.44)$.

Conclusion: Lower HL was associated with an increased risk of death. This finding should be considered carefully and confirmed by further research.

Keywords: Health literacy, Mortality, Correlation coefficient, Meta-analysis

\section{Background}

\section{Health literacy}

Health literacy (HL) is the result of the healthcare and education system, and social, cultural, economic, and other factors. Improving HL is considered to be one of the most fundamental, economical, and effective measures to improve the health level of the whole population [1]. The

\footnotetext{
* Correspondence: epicamu@163.com

${ }^{1}$ School of Public Health and Management, Chongqing Medical University, No.61 Daxuecheng Middle Road, Shapingba District, Chongqing 400016, China

Full list of author information is available at the end of the article
}

Institute of Medicine defines HL as "the degree to which individuals can obtain, process, and understand the basic health information and services they need to make appropriate health decisions" [2]. It involves not only reading and understanding, but also the use of printed information, numerical information, and language literacy, etc. [3]. Patients without these skills cannot provide adequate selfcare and may be at risk of higher mortality [4]. The 9th Global Conference on Health Promotion pointed out that $\mathrm{HL}$ is an important factor for ensuring improved health outcomes [5]. Low-level HL has long been regarded as a

(c) The Author(s). 2021 Open Access This article is licensed under a Creative Commons Attribution 4.0 International License, which permits use, sharing, adaptation, distribution and reproduction in any medium or format, as long as you give appropriate credit to the original author(s) and the source, provide a link to the Creative Commons licence, and indicate if changes were made. The images or other third party material in this article are included in the article's Creative Commons licence, unless indicated otherwise in a credit line to the material. If material is not included in the article's Creative Commons licence and your intended use is not permitted by statutory regulation or exceeds the permitted use, you will need to obtain permission directly from the copyright holder. To view a copy of this licence, visit http://creativecommons.org/licenses/by/4.0/ The Creative Commons Public Domain Dedication waiver (http://creativecommons.org/publicdomain/zero/1.0/) applies to the data made available in this article, unless otherwise stated in a credit line to the data. 
major obstacle to the effective management of cardiovascular diseases, affecting individual self-care skills and the health outcome of the patient, mainly in terms of doctorpatient communication, use of medical resources, quality of life, and mortality [6]. Inadequate HL has been linked with poor disease management, non-compliance with treatment recommendations, and medication errors by patients or caregivers. Whether for patients or medical workers, HL plays an irreplaceable role in disease prevention and management [7].

\section{Health literacy levels}

At present, the status of HL in the world is not optimistic. The European Health Literacy Survey (HLS-EU) Consortium conducted a wide range of HL surveys in eight EU member states between 2009 and 2012, and the results showed that $47 \%$ of the 7770 respondents had limited (insufficient or problematic) HL [8]. According to the 2003 International Adult Literacy and Life Skills Survey (IALSS), more than 12 million (60\%) adult Canadians lack HL; the overall level of HL in China in 2018 was $17 \%$ [9].

At the patient population level, adequate $\mathrm{HL}$ is the basis for disease prevention and management [10], but in fact HL of patients is not satisfactory. A meta analysis showed that among 13,457 patients with type 2 diabetes mellitus (T2DM), limited HL ranged from 7 to $82 \%$, the lowest in Switzerland and the highest in Taiwan. Pooled prevalence showed nearly one-third patients with T2DM in the USA had limited functional HL [11]. Pooled prevalence of limited HL was $25 \%$ among patients with chronic kidney disease [12]. A cross-sectional study in France showed that the prevalence of low HL in patients with acute decompensated heart failure and acute myocardial infarction was 51 and $21 \%$, respectively [13].

\section{Research justification}

Understanding the impact of HL is a priority for health promotion, prevention and treatment of chronic diseases. Patients with inadequate HL have limited ability to obtain health information and understand diseaserelated knowledge, lack of correct cognition of disease, and are prone to negative emotions, which affect the treatment effect and lead to adverse outcomes [14]. Studies have shown that inadequate HL is associated with increased emergency use and readmission rates [15]. Many scholars have investigated the relationship between HL and mortality, although the results are inconsistent. McNaughton et al. investigated 1379 patients with acute heart failure and found that lower levels of HL were associated with an increased risk of death after hospitalization for acute heart failure [16]. However, León-González et al. conducted a prospective study of 556 patients with comorbid heart failure in six hospitals in Spain, and the results showed that there was no association between HL and 12-month mortality [17]. Therefore, the aim of this study was to provide a comprehensive analysis of the literature regarding the association between HL and mortality.

\section{Methods}

We performed this review according to the recommendations of the Cochrane Collaboration and following the PRISMA Statement. The PROSPERO registration number is CRD42020203347.

\section{Search strategy}

Relevant studies were identified through the Web of Science Core Collection and PubMed databases by using the following search terms, and the search strategy was specific to each database: 1) health literacy: "health literacy" OR "healthy literacy" OR "literacy"; 2) mortality: "mortality" OR "death" OR "fatal". The searches were limited to full-length articles published in English, and the results were downloaded into Endnote X9.2 (Thomson Reuters (Scientific) LLC Philadelphia, PA). A more extensive and detailed search strategy is reported in Table 1.

\section{Inclusion and exclusion criteria}

Studies were selected if they met the following criteria: 1) the study assessed HL using a previously validated instrument; 2) the main outcome was death, including allcause mortality and special mortality; and 3) the study assessed the correlation between HL and mortality, and provided hazard ratio (HR), relative risk (RR), or odds ratio (OR) estimates and corresponding 95\% confidence intervals (CI). We excluded articles: 1) in languages other than English; 2) that were editorials, conference abstracts, letters, book news, or review articles; 3) in which HL or death was not measured; and 4) in which there was no correlation coefficient between $\mathrm{HL}$ and mortality provided. When more than one study reported results from the same cohort, the most recent and detailed studies were included in the analysis.

\section{Data collection}

First, two reviewers (Zhaoya F and Yang Y) independently screened the articles by title and abstract. Then, the full-text was read and the remaining articles were filtered again. Any disagreements in the process were resolved by consensus.

For each study included in the systematic review, we extracted the following data using a standardized form: first author, year of publication, study design, geographic location, source population, baseline age and sex of participants, subject ethnicity, duration of follow-up, number of deaths, how HL was evaluated, HR RR or OR and 
Table 1 Search methods for identification of studies: A systematic review and meta-analysis on the association between $\mathrm{HL}$ and mortality from 2006 to 2020

\begin{tabular}{|c|c|c|}
\hline Database & Search strategy & Results \\
\hline \multirow[t]{3}{*}{ Web of Science Core Collection } & \#1: TOPIC: ("health literacy") OR TOPIC: ("healthy literacy") OR TOPIC: (literacy) & 17411 \\
\hline & \#2: TOPIC: (mortality) OR TOPIC: (death) OR TOPIC: (fatal) & 1397471 \\
\hline & \#3: \#1 AND \#2 & 1170 \\
\hline \multirow[t]{4}{*}{ PubMed } & \#1: ((health literacy [MeSH Terms]) OR (healthy literacy [MeSH Terms]]) OR (literacy [MeSH Terms]) & 6558 \\
\hline & \#2: ((mortality [MeSH Terms]) OR (death [MeSH Terms])) OR (fatal [MeSH Terms]) & 514466 \\
\hline & \#3: \#1 AND \#2 & 65 \\
\hline & Total & 1235 \\
\hline
\end{tabular}

MeSH Medical Subject Headings

the corresponding 95\% CI, and adjustments for covariates.

\section{Quality assessment}

The quality of the original studies that were included in the meta-analysis was evaluated using the NewcastleOttawa Scale [18]. The quality assessment scale awards 0-13 points based on three perspectives: selection of study population, comparability, and outcome assessment. We considered studies with a total score of $\geq 9$ points to represent high quality. Scoring for quality assessment was independently conducted by two authors (Zhaoya F and Yang Y). Their results were compared and a third party (Zhang F) intervened if a consensus could not be reached.

\section{Statistical analysis}

Most studies divided patients into two categories based on similar cutoff points: adequate and inadequate HL. When the results of adequate, marginal, and inadequate HL were presented, we combined the inadequate and marginal HL categories according to previous studies, which have shown that any inadequate HL is a risk factor for outcomes. HR was used to measure the association between HL and mortality. When studies had not used the highest category as a reference, we recalculated the HRs and their 95\% CI relative to the highest category $[19,20]$. For studies that separately calculated the relationship between inadequate and marginal HL and mortality, we combined the HRs using the method reported by Hamling and then used the pooled HRs for the overall meta-analysis [21]. To combine the S-TOFHLA with other measurement tools to evaluate $\mathrm{HL}$, we chose the result of the S-TOFHLA assessment.

Inter-study heterogeneity was evaluated using Cochran's $X^{2}$-based $Q$ statistic, and inconsistency was quantified using the $\mathrm{I}^{2}$ statistic. $\mathrm{I}^{2}$ values of $0,25,50$, and $75 \%$ were considered as no, low, moderate, and high degrees of heterogeneity, respectively [22]. According to the Q-statistic, if no significant heterogeneity (defined as $\mathrm{I}^{2}<50 \%$ ) was found, the pooled HR estimate was determined with the fixed effects model; the random effects model was used in the case of significant heterogeneity. Stratification analyses by population, study design, area, time, and the types of HL instruments were conducted as a way of addressing inter-study heterogeneity. Sensitivity analysis was performed to ensure the stability of the results. Metaregression analysis was used to detect heterogeneity. The dependent variable of meta-regression was the correlation coefficient between HL and mortality, and population, study design, year of publication, and geographic location were independent variables. Publication bias was assessed using Egger's test [23]. Stata version 15.0 (Stata Corporation, College Station, TX, USA) was used for all the statistical analyses, and a two-tailed $P<0.05$ was assumed to be statistically significant.

\section{Results}

Initially, 1235 articles were identified. Sixty-nine were discarded after the first round screening of title and abstract. The main reason for exclusion was the failure to evaluate HL $(n=721)$ and mortality $(n=256)$. During the full-text review, 19 articles were selected and included in the systematic review. All the studies included were cohort studies. Specific reasons for exclusion and the selection procedure are shown in Fig. 1.

\section{Characteristics of included studies}

The included studies were published between 2006 and 2020. Eleven were prospective cohort studies [17, 24-33] and eight were retrospective cohort studies [16, 34-40]. Among these articles, 41,149 participants were involved, of which 5840 (14\%) died. The majority of the studies were undertaken in the United States [16, 34-40]. Four were carried out in the United Kingdom [27, 31, 34, 38], one in Spain [17], and one in Turkey [36]. Of the 19 studies, seven were conducted in the elderly [24, 27, 29, $30,34,38,39]$, six in patients with heart failure $[16,17$, $26,33,37,40]$, one in chronic kidney disease patients [31], one in cardiovascular disease patients [28], one in chronic hemodialysis patients [25], one in kidney transplant candidates [32], one in palliative care patients [36], 


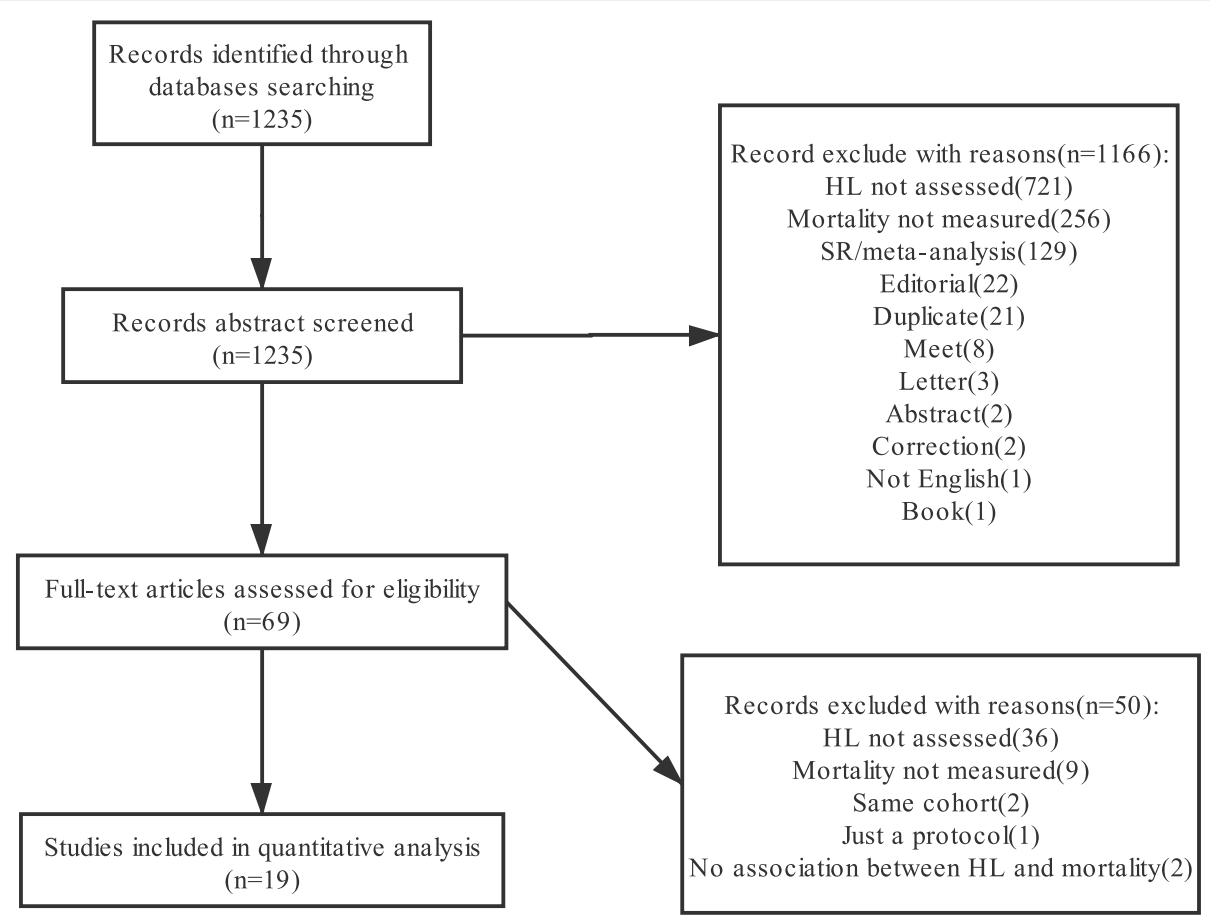

Fig. 1 Flowchart of study selection: A systematic review and meta-analysis on the association between HL and mortality from 2006 to 2020

and one in male veterans [35]. The length of follow-up ranged from 3 months to 8 years (one study [31] did not provide data on follow-up period). The quality ratings of the studies are shown in Table 2. All studies were of high quality. Table 2 summarizes the characteristics of the included studies.

\section{HL screening instruments}

Nine different instruments were used to screen HL in the studies included in this systematic review: the STOFHLA [24, 27, 28, 33, 39, 40], Rapid Estimate of Adult Literacy in Medicine (REALM) [25, 27, 30], Brief Health Literacy Screen (BHLS) [16, 26, 28, 31, 32, 37], Newest Vital Sign [35], Short Assessment of Health Literacy for Spanish-speaking Adults [17], 3-item version of the Subjective Numeracy Scale [28], Health Literacy Survey-European Union-Questionnaire [36], a brief 4item comprehension test based on instructions similar to those found on a packet of aspirin bought over the counter [38], general functional HL [27] and a 9-item instrument [29]. Two articles [27, 28] used more than one tool to measure HL. The most commonly used HL screening instrument was the S-TOFHLA and the BHLS, used in six studies.

The S-TOFHLA is a shortened version of the Test of Functional Health Literacy in Adults that includes two reading passages (36 items worth 2 points each) and four numeracy items (7 points each) [41]. This test is an objective test in which respondents choose words missing from text representing medical directions and information about health care, and the sum of the two parts yields the S-TOFHLA score, ranging from 0 to 100 . The reading comprehension part of this test is mainly reading materials in the hospital environment, such as informed consent and label of a medicine bottle, and a calculation part assessing the patient's numerical comprehension ability such as understanding blood glucose measurement values and financial subsidies. The STOFHLA divides respondents into three categories depending on scores: $0-55,56-66$, and $67-100$, corresponding to inadequate literacy, marginal literacy, and adequate literacy, respectively.

The BHLS is a subjective measure, which consists of three items, asking patients to report their level of confidence filling out medical forms, need for assistance in reading hospital materials, and understanding of written medical information [42]. The specific questions are: 1) "How often do you have someone help you read hospital materials?", 2) "How often do you have problems learning about your medical condition because of difficulty reading hospital materials?", and 3) "How confident are you filling out forms by yourself?" Each question was scored by patients on a 5 -point scale, in which higher scores indicated lower literacy. Compared with STOFHLA, the brief screener is less time-consuming and easier to implement in clinical practice.

The REALM is a word recognition and pronunciation test based on the correct pronunciation of 66 common 


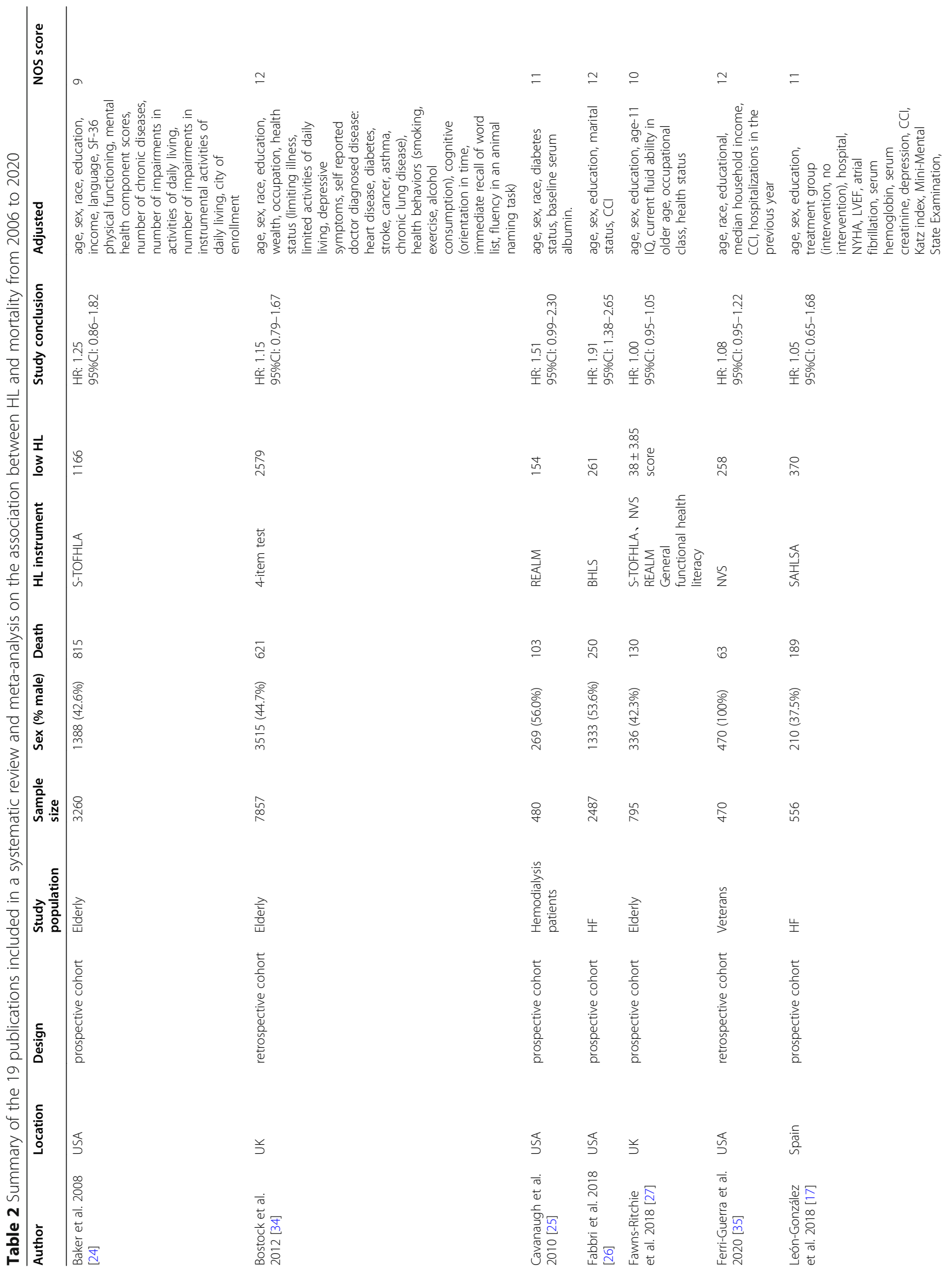




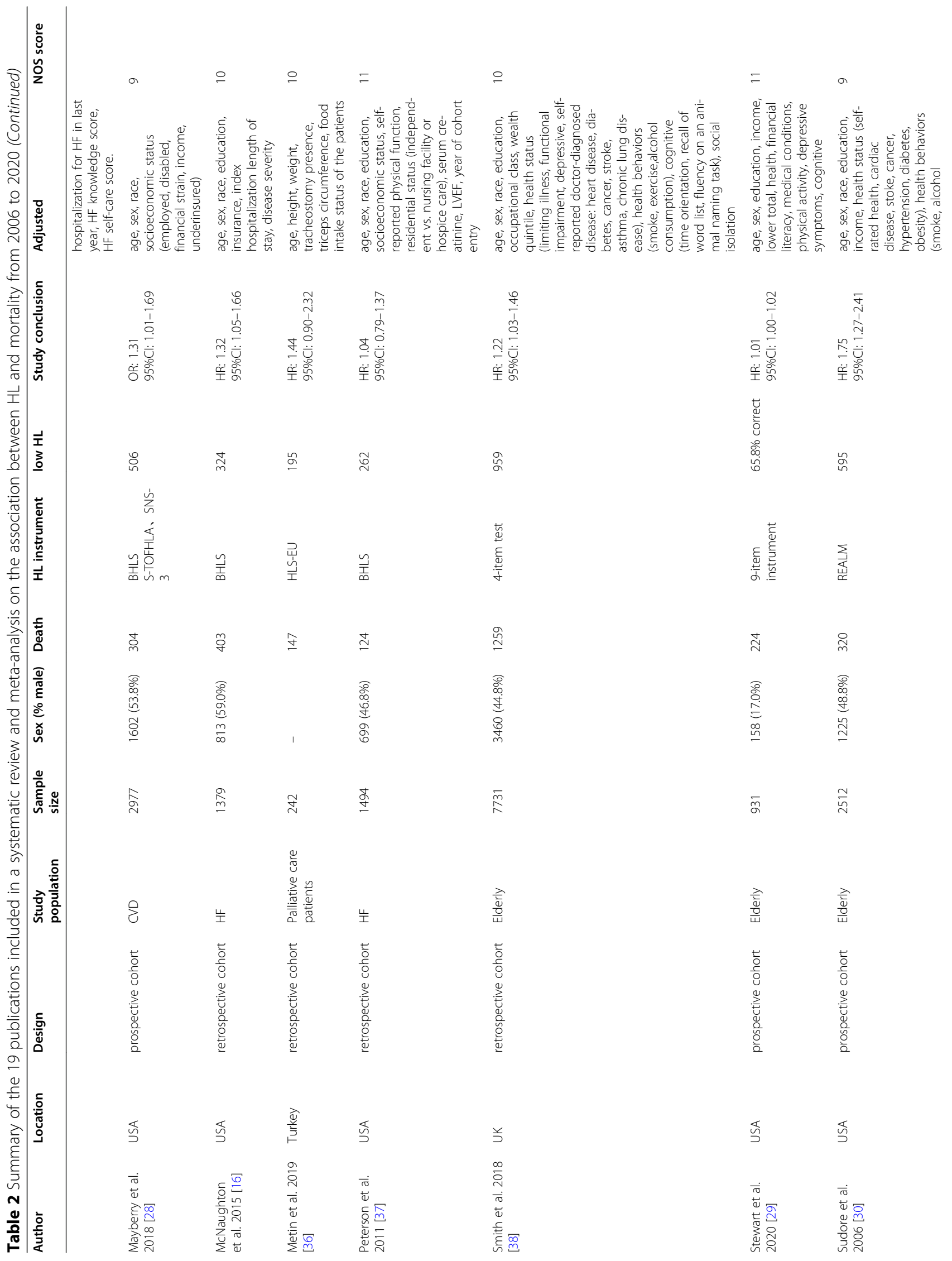




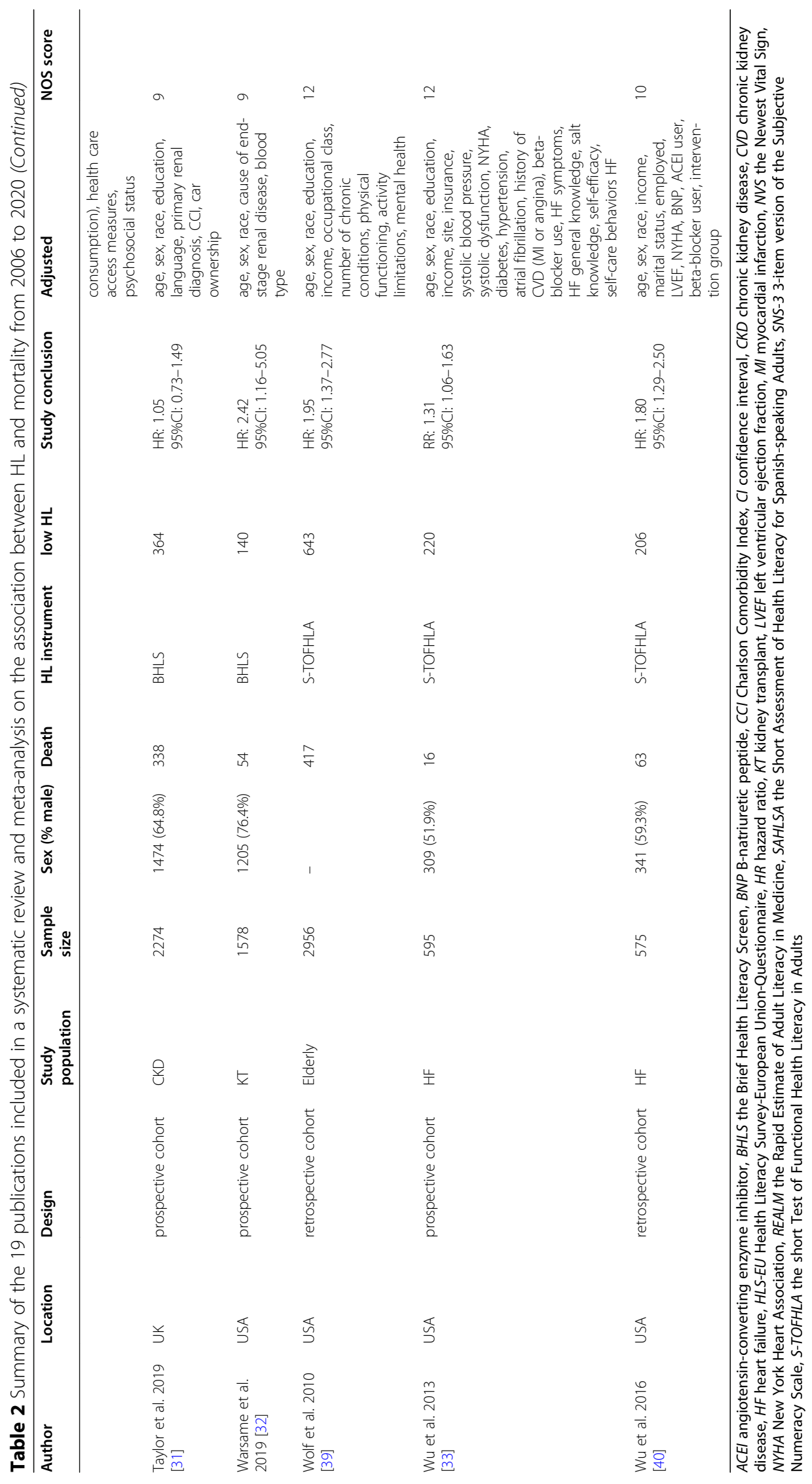


medical terms designed for use in health care settings. The original REALM was developed in 1991 by Davis and consisted of 125 common medical terms [43]. The test format was revised in 1993, and the list of words was shortened to 66 items [44]. Participants are presented a piece of paper with a list of 66 medical words and are asked to read these words aloud. The words range in difficulty from easy ('fat') to difficult ('impetigo'). One point is given for each correct response. A score of 59 or less is defined as indicating low HL, while a score of 60 or more indicates adequate HL. Many derivative versions have been developed to meet different needs. Lee et al. developed the Short Assessment of Health Literacy for Spanish-speaking Adults for the Spanish-speaking language group [45].

\section{$\mathrm{HL}$ and mortality Overall analysis}

In the heterogeneity test, the correlation between $\mathrm{HL}$ and mortality $\left(\mathrm{I}^{2}=78.5 \%, P<0.001\right)$ showed that there was heterogeneity, using a random effects model to combine effect quantity. Based on the combined results of the 19 cohort studies, compared with the adequate category, inadequate or marginal categories experienced significantly increased risk of death $(\mathrm{HR}=1.25,95 \% \mathrm{CI}=$ 1.15-1.35) (Fig. 2).

\section{Subgroup analysis}

The subgroup analysis included population, study design, area, time, and the types of HL instruments (Table 3). For studies conducted in patients with heart failure (HF), the meta-analysis revealed a significantly increased risk of death among inadequate or marginal HL categories as compared to the adequate HL category $\left(\mathrm{HR}=1.37,95 \% \mathrm{CI}=1.14-1.65 ; \quad P<0.001 ; \mathrm{I}^{2}=57.9 \%\right)$. Noticeably, the correlation coefficient between HL and mortality was $1.20\left(95 \% \mathrm{CI}=1.09-1.32 ; P<0.001 ; \mathrm{I}^{2}=\right.$ $78.1 \%)$ based on the prospective cohort study design and 1.38 (95\% CI $\left.=1.20-1.59 ; \quad P<0.001 ; \mathrm{I}^{2}=84.3 \%\right)$ in the USA.

One study assessed HL using four separate tools, and each provided an association between HL and mortality. When subgroup analysis was conducted according to HL instruments, we used different models for analysis. The asterisk indicates the different tools used in the study, and we chose the results of S-TOFHLA assessment in other subgroup analyses.

\section{Sensitivity analysis and meta-regression analysis}

Sensitivity analyses were used to evaluate the effect of each study on the pooled results by sequentially excluding single studies. The results did not significantly change after excluding each study (Table 4).

To identify the possible sources of heterogeneity, different factors associated with heterogeneity, such as

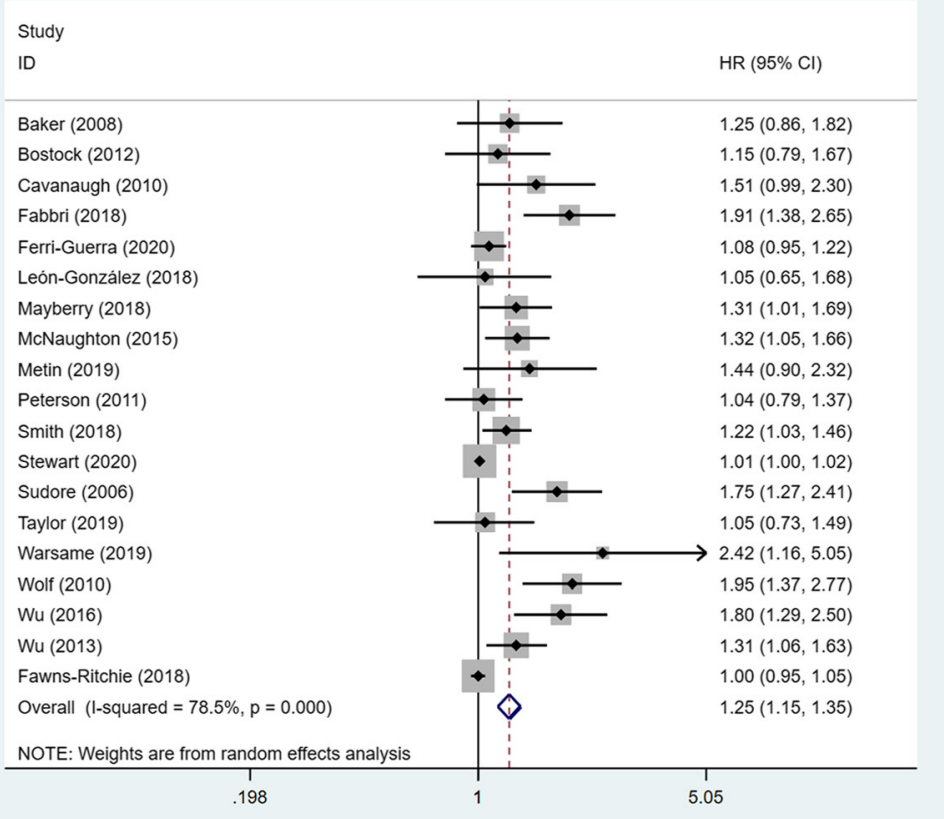

Fig. 2 Forest plot of HL and risk of death: A systematic review and meta-analysis on the association between HL and mortality from 2006 to 2020 
Table 3 Subgroup analysis of a systematic review and metaanalysis on the association between $\mathrm{HL}$ and mortality from 2006 to 2020

\begin{tabular}{|c|c|c|c|c|}
\hline Subgroup & No. of studies & $\mathrm{HR}(95 \% \mathrm{Cl})$ & $P$ & $1^{2}$ \\
\hline Total & 19 & $1.25(1.15-1.35)$ & $<0.001$ & $78.5 \%$ \\
\hline \multicolumn{5}{|l|}{ Population } \\
\hline Elderly & 7 & $1.14(1.04-1.25)$ & $<0.001$ & $80.6 \%$ \\
\hline Heart failure & 6 & $1.37(1.14-1.65)$ & 0.036 & $57.9 \%$ \\
\hline \multicolumn{5}{|l|}{ Design } \\
\hline Prospective & 11 & $1.20(1.09-1.32)$ & $<0.001$ & $78.1 \%$ \\
\hline Retrospective & 8 & $1.30(1.12-1.50)$ & 0.012 & $61.3 \%$ \\
\hline \multicolumn{5}{|l|}{ Location } \\
\hline USA & 13 & $1.38(1.20-1.59)$ & $<0.001$ & $84.3 \%$ \\
\hline UK & 4 & $1.07(0.95-1.21)$ & 0.167 & $40.7 \%$ \\
\hline \multicolumn{5}{|l|}{ Time } \\
\hline Before 2016.12 & 9 & $1.40(1.22-1.61)$ & 0.008 & $43.2 \%$ \\
\hline After 2017.1 & 10 & $1.11(1.03-1.20)$ & $<0.001$ & $71.7 \%$ \\
\hline \multicolumn{5}{|l|}{ HL questionnaire } \\
\hline \multicolumn{5}{|l|}{ Model 1} \\
\hline S-TOFHLA* & 5 & $1.38(1.05-1.83)$ & $<0.001$ & $86.9 \%$ \\
\hline BHLS & 5 & $1.36(1.05-1.77)$ & 0.017 & $66.6 \%$ \\
\hline REALM & 2 & $1.66(1.28-2.14)$ & 0.585 & $0.0 \%$ \\
\hline NVS & 1 & $1.08(0.95-1.22)$ & - & - \\
\hline Others & 6 & $1.14(1.00-1.31)$ & 0.051 & $54.6 \%$ \\
\hline \multicolumn{5}{|l|}{ Model 2} \\
\hline S-TOFHLA & 4 & $1.52(1.23-1.89)$ & 0.126 & $47.5 \%$ \\
\hline BHLS & 5 & $1.36(1.05-1.77)$ & 0.017 & $66.6 \%$ \\
\hline REALM* & 3 & $1.35(0.89-2.03)$ & 0.001 & $85.9 \%$ \\
\hline NVS & 1 & $1.08(0.95-1.22)$ & - & - \\
\hline Others & 6 & $1.14(1.00-1.31)$ & 0.051 & $54.6 \%$ \\
\hline \multicolumn{5}{|l|}{ Model 3} \\
\hline S-TOFHLA & 4 & $1.52(1.23-1.89)$ & 0.126 & $47.5 \%$ \\
\hline BHLS & 5 & $1.36(1.05-1.77)$ & 0.017 & $66.6 \%$ \\
\hline REALM & 2 & $1.66(1.28-2.14)$ & 0.585 & $0.0 \%$ \\
\hline NVS* & 2 & $1.02(0.91-1.14)$ & 0.182 & $43.7 \%$ \\
\hline Others & 6 & $1.14(1.00-1.31)$ & 0.051 & $54.6 \%$ \\
\hline \multicolumn{5}{|l|}{ Model 4} \\
\hline S-TOFHLA & 4 & $1.52(1.23-1.89)$ & 0.126 & $47.5 \%$ \\
\hline BHLS & 5 & $1.36(1.05-1.77)$ & 0.017 & $66.6 \%$ \\
\hline REALM & 2 & $1.66(1.28-2.14)$ & 0.585 & $0.0 \%$ \\
\hline NVS & 1 & $1.08(0.95-1.22)$ & - & - \\
\hline Others* & 7 & $1.11(0.99-1.24)$ & 0.082 & $46.5 \%$ \\
\hline
\end{tabular}

${ }^{*}$ represent the tool used in the analysis

population, study design, year of publication, and geographic location, were computed using meta-regression models, although none of these variables were statistically significant.
Table 4 Sensitivity analysis of a systematic review and metaanalysis on the association between HL and mortality from 2006 to 2020

\begin{tabular}{lllll}
\hline Omitting study & HR & 95\%Cl & $\boldsymbol{P}$ & $\mathbf{I}^{\mathbf{2}}$ \\
\hline Baker et al. 2008 [24] & 1.25 & $1.15-1.35$ & $<0.001$ & $79.4 \%$ \\
Bostock et al. 2012 [34] & 1.25 & $1.15-1.36$ & $<0.001$ & $79.6 \%$ \\
Cavanaugh et al. 2010 [25] & 1.24 & $1.14-1.34$ & $<0.001$ & $78.8 \%$ \\
Fabbri et al. 2018 [26] & 1.21 & $1.12-1.31$ & $<0.001$ & $75.4 \%$ \\
Fawns-Ritchie et al. 2018 [27] & 1.32 & $1.18-1.48$ & $<0.001$ & $79.6 \%$ \\
Ferri-Guerra et al. 2020 [35] & 1.27 & $1.16-1.39$ & $<0.001$ & $79.4 \%$ \\
León-González et al. 2018 [17] & 1.25 & $1.15-1.36$ & $<0.001$ & $79.7 \%$ \\
Mayberry et al. 2018 [28] & 1.24 & $1.14-1.35$ & $<0.001$ & $78.7 \%$ \\
McNaughton et al. 2015 [16] & 1.24 & $1.14-1.35$ & $<0.001$ & $78.3 \%$ \\
Metin et al. 2019 [36] & 1.24 & $1.14-1.35$ & $<0.001$ & $79.1 \%$ \\
Peterson et al. 2011 [37] & 1.26 & $1.16-1.37$ & $<0.001$ & $79.7 \%$ \\
Smith et al. 2018 [38] & 1.25 & $1.15-1.36$ & $<0.001$ & $78.6 \%$ \\
Stewart et al. 2020 [29] & 1.32 & $1.18-1.47$ & $<0.001$ & $75.1 \%$ \\
Sudore et al. 2006 [30] & 1.22 & $1.13-1.32$ & $<0.001$ & $76.5 \%$ \\
Taylor et al. 2019 [31] & 1.26 & $1.16-1.36$ & $<0.001$ & $79.7 \%$ \\
Warsame et al. 2019 [32] & 1.23 & $1.14-1.34$ & $<0.001$ & $78.3 \%$ \\
Wolf et al. 2010 [39] & 1.22 & $1.12-1.31$ & $<0.001$ & $75.8 \%$ \\
Wu et al. 2013 [33] & 1.22 & $1.13-1.32$ & $<0.001$ & $76.4 \%$ \\
Wu et al. 2016 [40] & 1.24 & $1.14-1.35$ & $<0.001$ & $78.3 \%$ \\
\hline
\end{tabular}

\section{Publication bias}

The publication bias test indicated significant publication bias. A funnel plot (Fig. 3) showed visual evidence of asymmetry, which was consistent with Egger's regression symmetry test $(P<0.001)$, and we adjusted for the effect of publication bias by using the Duval and Tweedie's nonparametric trim-and-fill method, which imputes hypothetical small missing null or negative studies [46]. After imputing eight missing studies, a symmetrical funnel plot was obtained (Fig. 4).

\section{Discussion}

Low HL has important implications for wellness, increasing the risk of negative health outcomes, and is also an invisible barrier to health care services that has profound costs for individual and public health. With the development of medical technology and the increase in life expectancy, people pay more attention to their level of HL. Most researchers believe that HL is an important predictor of health status (even stronger than income, career, and education) [47]. Therefore, it is important to pay attention to improving HL in the population. The first step in overcoming the impact of low HL in the population is to recognize the high prevalence of limited HL [48]. For example, during hospital visits, surgeons should seek to enhance patient understanding, avoid 
Begg's funnel plot with pseudo $95 \%$ confidence limits

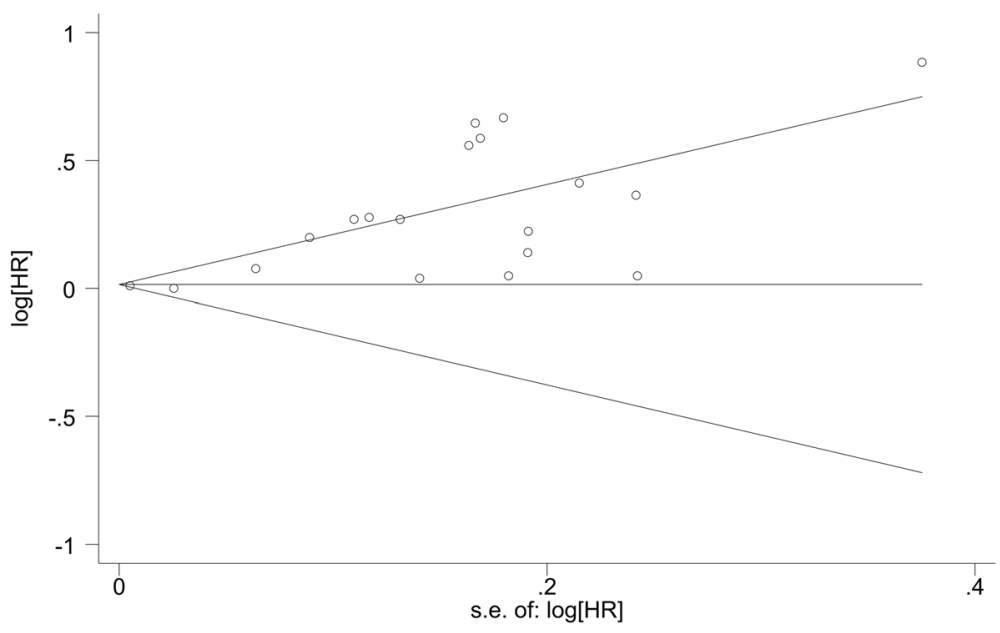

Fig. 3 Funnel plot of a systematic review and meta-analysis on the association between $\mathrm{HL}$ and mortality from 2006 to 2020

using technical medical terminology, and encourage patients to participate in care discussions.

This study is a systematic review and meta-analysis of HL levels in the whole population. Among 39,423 subjects (two articles $[27,29]$ did not report the number of low HL), approximately $9202(23 \%)$ had inadequate or marginal HL. In other studies, a similar conclusion was reached. Paasche-Orlowl et al. systematically reviewed the USA studies and examined the prevalence of limited HL; 31,129 subjects were involved, and a low prevalence of HL between 0 and $68 \%$ was reported. Pooled analyses of these data revealed that the weighted prevalence of low HL was $26 \%$ and that of marginal HL was $20 \%$ [49]. For six studies conducted in HF patient samples, the prevalence of inadequate or marginal HL was $17 \%$. In a previous systematic review conducted by Fabbri et al. [50], it was found that an average of $24 \%$ of HF patients had inadequate or marginal HL. Our result was slightly lower than this.

Previous studies have shown that the most common demographic features reported to be associated with $\mathrm{HL}$ are age, ethnicity, and geographic location [49]. Our study showed that inadequate HL was associated with a higher risk of mortality. In contrast, three articles did not find an association between $\mathrm{HL}$ and mortality. One study was conducted only in male veterans [35], one was conducted in Spain in HF patients [17], and one was conducted in the UK in chronic kidney disease patients

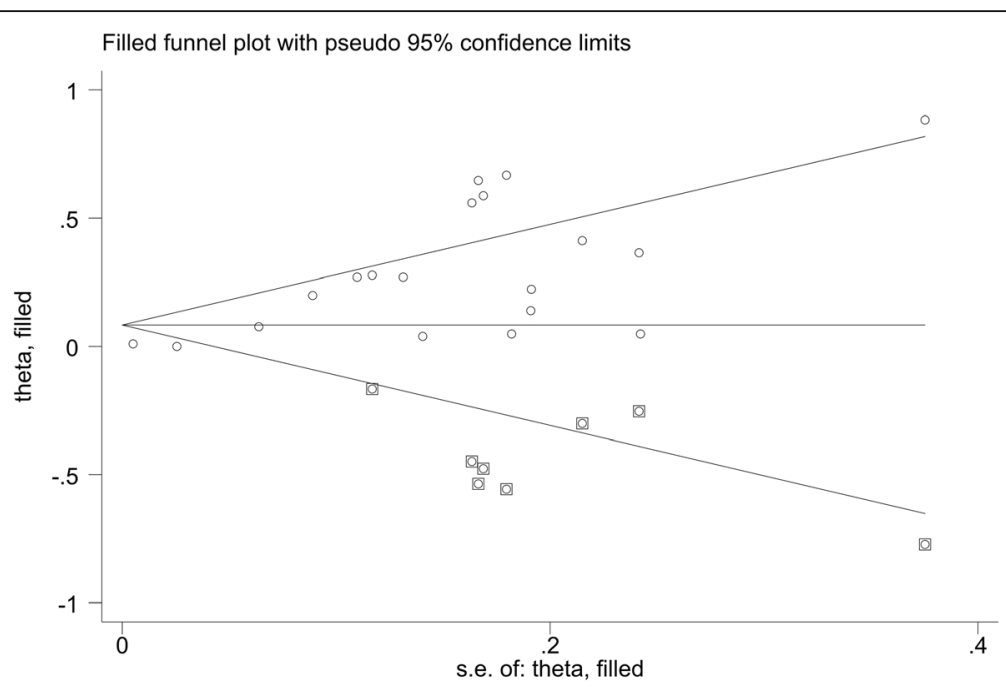

Fig. 4 Trim and fill method for evaluating publication bias (The circles alone are real studies and the circles enclosed in boxes are 'filled' studies. The horizontal line represents the summary effect estimates, and the diagonal lines represent pseudo- $95 \% \mathrm{Cl}$ limits): A systematic review and meta-analysis on the association between $\mathrm{HL}$ and mortality from 2006 to 2020 
[31]. These may be the reasons for the different conclusions, reflecting two factors: different care delivery systems may be a factor in the outcome, underscoring the need for further studies to be conducted in different countries; and mortality has high statistical heterogeneity, which may be caused by the different populations in the studies.

Nine different instruments were used to screen HL in the studies included in this systematic review. Instruments vary in how they transform the concept of HL into a measurable construct. Most measures involve only limited conceptual dimensions of HL. The time and resources required to implement measures vary considerably across the measures. Scoring approaches and categories of $\mathrm{HL}$ on the basis of performance measures also vary. It is worth noting that the studies included in this review conceptually defined HL in a variety of ways. Five of the studies $[16,24,30,31,34]$ failed to provide a conceptual definition of HL; 12 of the studies [17, 25$27,29,32,34,36-40]$ simply defined HL as "the degree to which individuals have the capacity to obtain, process, and understand basic health information and services needed to make basic health decisions", failing to recognize the multifaceted nature of HL that goes beyond these abilities. The rest $[28,35]$ recognized $\mathrm{HL}$ as a multidimensional process, incorporating systemic demands and complexities as well as individuals' skills and abilities, and may encompass numerical and graphical literacy. The differences in the conceptual definitions provided are not surprising given that there is no universal consensus on the definition of HL. Regardless of differing opinions, most experts agree that HL is more than just the ability to read and comprehend health information. At the same time, among the population surveyed, the pooled estimate might overestimate the actual prevalence of low HL. For studies where most of the subjects were patients, they excluded patients who could not speak or understand English, and those with cognitive impairment. In addition, the studies required signed informed consent, which could have discouraged patients with low HL from participating in the studies, given that most consent forms are written at a 10th-grade reading level. Various interventions and screening instruments, as well as the variety of outcome parameters across many time periods, mitigated the use of meta-analysis, so caution should be taken when interpreting the findings presented in this review.

Due to the heterogeneity observed among the included studies, pooled estimates were calculated using the random effects model for both the overall analysis and for several of the subgroup analyses. This model assumes that the underlying true effects differ between studies. Sources of heterogeneity could include differences in participant characteristics across studies, study design factors, and variations in the metrics ( $R R$ versus $H R$ ) used to measure outcomes. For the present study, using sensitivity analysis, no study was found to significantly contribute to the heterogeneity.

Finally, publication bias was detected; the funnel plot revealed an apparent asymmetry that suggested the presence of a potential publication bias, a language bias, inflated estimates by a flawed method logic design in smaller studies, and/or a lack of publication of small trials with opposite results.

\section{Study strengths and limitations}

The strengths of this study that lend weight to our conclusions are the large sample size and the use of validated literacy assessment instruments in almost all studies. The results of the present analysis are intended to provide more robust evidence than any individual study. However, some limitations may have influenced the findings, in that heterogeneity was observed among the included studies and publication bias could not be avoided. Second, the included studies assessed levels of HL with different tools. Although we conducted a stratified analysis based on the type of instrument, it may still affect comparability because subjective and objective measurement tools may have different focuses. Finally, due to the author's inability to review non-English manuscripts, only English articles were included in this study, which may result in the loss of some studies.

\section{Suggestions for further studies}

Most of the studies were conducted in the USA, which limits the generalizability of the findings to other countries with different healthcare systems and social structures. Future research should be conducted in different countries and regions to increase the generalizability. Second, future studies should consider the use of a more complete measure of $\mathrm{HL}$, one that measures all the dimensions of HL and not only reading comprehension.

\section{Conclusions}

The prevalence of low HL ranged from 9 to $81 \%$ (two articles [27, 29] did not report the number of low HL), with an average of $23 \%$ of the study participants found to have low HL. This meta-analysis suggests that HL is associated with mortality. However, this conclusion needs to be supported by further evidence. Considering the increasing prevalence of inadequate HL worldwide and the heavy burdens of death, it is essential to simplify health services and improve health education. Our findings may provide valuable clues for related research in the future.

\section{Abbreviations}

BHLS: the Brief Health Literacy Screen; Cl: Confidence Interval; HL: Health Literacy; HR: Hazard Ratio; OR: Odds Ratio; REALM: the Rapid Estimate of 
Adult Literacy in Medicine; RR: Relative Risk; S-TOFHLA: the Short Test of Functional Health Literacy in Adults

\section{Acknowledgements}

We would like to thank all authors of the studies included in this systematic review and meta-analysis.

\section{Authors' contributions}

YY and FZ conceived the study. ZYF was participated in its design, and performed result writing, analyzing the finding and writing the manuscript. YY and FZ also involved in data extraction and analysis. All authors read and approved the final version of this protocol.

\section{Funding}

No funding was obtained for this study.

Availability of data and materials

All relevant data are within the paper and its Supporting Information files.

\section{Declarations}

\section{Ethics approval and consent to participate}

Not applicable.

\section{Consent for publication}

Not applicable.

\section{Competing interests}

The authors declare that they have no competing interests.

\section{Author details}

${ }^{1}$ School of Public Health and Management, Chongqing Medical University, No.61 Daxuecheng Middle Road, Shapingba District, Chongqing 400016, China. ${ }^{2}$ Department of Cardiovascular Medicine, The First Affiliated Hospital of Chongqing Medical University, Chongqing 400016, China.

\section{Received: 7 December 2020 Accepted: 21 June 2021}

Published online: 01 July 2021

\section{References}

1. Parnell TA, Stichler JF, Barton AJ, Loan LA, Boyle DK, Allen PE. A concept analysis of health literacy. Nurs Forum. 2019;54(3):315-27. https://doi.org/1 $0.1111 /$ nuf.12331.

2. Nielsen-Bohlman L, Panzer AM, Kindig DA. Health literacy: a prescription to end confusion. Washington (DC): National Academies Press (US); 2004.

3. Juvinyà-Canal $D$, Suñer-Soler $R$, Boixadós Porquet $A$, Vernay $M, B$ lanchard $H$, Bertran-Noguer C. Health literacy among health and social care University students. Int J Environ Res Public Health. 2020;17:2273.

4. Rafferty AP, Winterbauer NL, Luo H, Bell RA, Little NRG. Diabetes self-care and clinical care among adults with low health literacy. J Public Health Manag Pract. 2021;27(2):144-53. https://doi.org/10.1097/PHH.0000000000001 050.

5. World Health Organization (WHO). Shanghai declaration on promoting health in the 2030 agenda for sustainable development. 2016. https://www. who.int/healthpromotion/conferences/9gchp/shanghai-declaration/zh/. Accessed 14 Oct 2020

6. Heine $M$, Lategan $F$, Erasmus $M$, et al. Health education interventions to promote health literacy in adults with selected non-communicable diseases living in low-to-middle income countries: A systematic review and metaanalysis [published online ahead of print, 2021 Mar 22]. J Eval Clin Pract. 2021. https://doi.org/10.1111/jep.13554.

7. Wittenberg E, Ferrell B, Kanter E, Buller H. Health literacy: exploring nursing challenges to providing support and understanding. Clin J Oncol Nurs. 2018;22(1):53-61. https://doi.org/10.1188/18.CJON.53-61.

8. Sørensen K, Pelikan JM, Röthlin F, Ganahl K, Slonska Z, Doyle G, et al. Health literacy in Europe: comparative results of the European health literacy survey (HLS-EU). Eur J Pub Health. 2015;25(6):1053-8. https://doi.org/10.1 093/eurpub/ckv043.

9. Statistics Canada. International adult literacy and skills survey (IALSS). 2005. https://www23.statcan.gc.ca/imdb/p2SV.pl?Function=getSurvey\&ld=15034. Accessed 14 Oct 2020
10. Poureslami I, Nimmon L, Rootman I, Fitzgerald MJ. Health literacy and chronic disease management: drawing from expert knowledge to set an agenda. Health Promot Int. 2017;32(4):743-54. https://doi.org/10.1093/hea pro/daw003.

11. Abdullah A, Liew SM, Salim H, Ng CJ, Chinna K. Prevalence of limited health literacy among patients with type 2 diabetes mellitus: a systematic review. PLoS One. 2019;14(5):e0216402. https://doi.org/10.13 71/journal.pone.0216402.

12. Taylor DM, Fraser SDS, Bradley JA, Bradley C, Draper H, Metcalfe W, et al. A systematic review of the prevalence and associations of limited health literacy in CKD. Clin J Am Soc Nephrol. 2017;12(7):1070-84. https://doi.org/1 0.2215/CJN.12921216.

13. Perrin A, Abdalla G, Viprey M, Delahaye F, Mewton N, Ovize M, et al. Prevalence of low health literacy levels in decompensated heart failure compared with acute myocardial infarction patients. ESC Heart Fail. 2021; 8(2):1446-59. https://doi.org/10.1002/ehf2.13230.

14. Rafferty AP, Luo H, Winterbauer NL, Bell RA, Little NRG, Imai S. Health Literacy Among Adults With Multiple Chronic Health Conditions [published online ahead of print, 2021 Apr 30]. J Public Health Manag Pract. 2021. https://doi.org/10.1097/PHH.0000000000001352.

15. Berkman ND, Sheridan SL, Donahue KE, Halpern DJ, Crotty K. Low health literacy and health outcomes: an updated systematic review. Ann Intern Med. 2011;155(2):97-107. https://doi.org/10.7326/0003-4819-155-2-2011071 90-00005

16. McNaughton CD, Cawthon C, Kripalani S, Liu D, Storrow AB, Roumie CL. Health literacy and mortality: a cohort study of patients hospitalized for acute heart failure. J Am Heart Assoc. 2015;4:e001799.

17. León-González R, García-Esquinas E, Paredes-Galán E, et al. Health literacy and health outcomes in very old patients with heart failure. Rev Esp Cardiol (English Edition). 2018;71:178-84.

18. Stang A. Critical evaluation of the Newcastle-Ottawa scale for the assessment of the quality of nonrandomized studies in meta-analyses. Eur J Epidemiol. 2010;25(9):603-5. https://doi.org/10.1007/s10654-010-9491-z.

19. Altman DG, Bland JM. How to obtain the $P$ value from a confidence interval. BMJ. 2011;343(aug08 1):d2304. https://doi.org/10.1136/bmj.d2304.

20. Altman DG, Bland JM. How to obtain the confidence interval from a $P$ value. BMJ. 2011;343(aug08 1):d2090. https://doi.org/10.1136/bmj.d2090.

21. Hamling J, Lee $P$, Weitkunat $R$, Ambühl M. Facilitating meta-analyses by deriving relative effect and precision estimates for alternative comparisons from a set of estimates presented by exposure level or disease category. Stat Med. 2008;27(7):954-70. https://doi.org/10.1002/sim.3013.

22. Higgins JPT, Thompson SG. Quantifying heterogeneity in a meta-analysis. Stat Med. 2002;21(11):1539-58. https://doi.org/10.1002/sim.1186.

23. Egger M, Smith GD, Schneider M, Minder C. Bias in meta-analysis detected by a simple, graphical test. BMJ. 1997;315(7109):629-34. https://doi.org/1 0.1136/bmj.315.7109.629

24. Baker DW, Wolf MS, Feinglass J, Thompson JA. Health literacy, cognitive abilities, and mortality among elderly persons. J Gen Intern Med. 2008;23(6): 723-6. https://doi.org/10.1007/s11606-008-0566-4

25. Cavanaugh KL, Wingard RL, Hakim RM, Eden S, Shintani A, Wallston KA, et al. Low health literacy associates with increased mortality in ESRD. J Am Soc Nephrol. 2010;21(11):1979-85. https://doi.org/10.1681/ASN.2009111163.

26. Fabbri M, Yost K, Rutten LJF, et al. Health literacy and outcomes in patients with heart failure: a prospective community study. Mayo Clin Proc. 2018; 93(1):9-15. https://doi.org/10.1016/j.mayocp.2017.09.018.

27. Fawns-Ritchie C, Starr JM, Deary IJ. Role of cognitive ability in the association between functional health literacy and mortality in the Lothian birth cohort 1936: a prospective cohort study. BMJ. 2018;8:e22502.

28. Mayberry LS, Schildcrout JS, Wallston KA, Goggins K, Mixon AS, Rothman RL, et al. Health literacy and 1-year mortality: mechanisms of Association in Adults Hospitalized for cardiovascular disease. Mayo Clin Proc. 2018;93(12): 1728-38. https://doi.org/10.1016/..mayocp.2018.07.024.

29. Stewart CC, Yu L, Lamar M, Wilson RS, Bennett DA, Boyle PA. Associations of health and financial literacy with mortality in advanced age. Aging Clin Exp Res. 2020;32(5):951-7. https://doi.org/10.1007/s40520-019-01259-7.

30. Sudore RL, Yaffe K, Satterfield S, Harris TB, Mehta KM, Simonsick EM, et al. Limited literacy and mortality in the elderly the health, aging, and body composition study. J Gen Intern Med. 2006;21(8):806-12. https://doi.org/1 0.1111/j.1525-1497.2006.00539.x.

31. Taylor DM, Bradley JA, Bradley C, Draper H, Dudley C, Fogarty D, et al. Limited health literacy is associated with reduced access to kidney 
transplantation. Kidney Int. 2019;95(5):1244-52. https://doi.org/10.1016/j. kint.2018.12.021.

32. Warsame F, Haugen CE, Ying H, Garonzik-Wang JM, Desai NM, Hall RK, et al. Limited health literacy and adverse outcomes among kidney transplant candidates. Am J Transplant. 2019;19(2):457-65. https://doi.org/10.1111/a jt.14994.

33. Wu J, Holmes GM, DeWalt DA, et al. Low literacy is associated with increased risk of hospitalization and death among individuals with heart failure. J Gen Intern Med. 2013;28(9):1174-80. https://doi.org/10.1007/s11 606-013-2394-4.

34. Bostock S, Steptoe A. Association between low functional health literacy and mortality in older adults: longitudinal cohort study. BMJ. 2012; 344(mar15 3):e1602. https://doi.org/10.1136/bmj.e1602.

35. Ferri-Guerra J, Mohammed YN, Aparicio-Ugarriza R, Salguero D, Shah A, Baskaran D, et al. The association of health literacy domains with hospitalizations and mortality. Am J Manag Care. 2020;26(5):200-6. https:/ doi.org/10.37765/ajmc.2020.43152.

36. Metin S, Demirci H, Metin AT. Effect of health literacy of caregivers on survival rates of patients under palliative care. Scand J Caring Sci. 2019;33(3): 669-76. https://doi.org/10.1111/scs.12662.

37. Peterson PN, Shetterly SM, Clarke CL, et al. Health literacy and outcomes among patients with heart failure. JAMA. 2011;16:1695-701.

38. Smith SG, Jackson SE, Kobayashi LC, Steptoe A. Social isolation, health literacy, and mortality risk: findings from the English longitudinal study of ageing. Health Psychol. 2018;37(2):160-9. https://doi.org/10.1037/hea 0000541.

39. Wolf MS, Feinglass J, Thompson J, Baker DW. In search of 'low health literacy': threshold vs. gradient effect of literacy on health status and mortality. Soc Sci Med. 2010;70(9):1335-41. https://doi.org/10.1016/j. socscimed.2009.12.013.

40. Wu J, Moser DK, DeWalt DA, Rayens MK, Dracup K. Health literacy mediates the relationship between age and health outcomes in patients with heart failure. Circ Heart Fail. 2016;9:e002250.

41. Baker DW, Williams MV, Parker RM, Gazmararian JA, Nurss J. Development of a brief test to measure functional health literacy. Patient Educ Couns. 1999; 38(1):33-42. https://doi.org/10.1016/50738-3991(98)00116-5.

42. Chew LD, Bradley KA, Boyko EJ. Brief questions to identify patients with inadequate health literacy. Fam Med. 2004;36(8):588-94.

43. Davis TC, Crouch MA, Long SW, Jackson RH, Bates P, George RB, et al. Rapid assessment of literacy levels of adult primary care patients. Fam Med. 1991; 23(6):433-5.

44. Davis TC, Long SW, Jackson RH, Mayeaux EJ, George RB, Murphy PW, et al. Rapid estimate of adult literacy in medicine: a shortened screening instrument. Fam Med. 1993;25(6):391-5.

45. Lee SD, Bender DE, Ruiz RE, Cho YI. Development of an easy-to-use Spanish health literacy test. Health Serv Res. 2006;41(4 Pt 1):1392-412. https://doi. org/10.1111/j.1475-6773.2006.00532.x.

46. Duval $\mathrm{S}$, Tweedie R. Trim and fill: a simple funnel-plot-based method of testing and adjusting for publication bias in meta-analysis. Biometrics. 2000; 56(2):455-63. https://doi.org/10.1111/j.0006-341X.2000.00455.X

47. Watts SA, Stevenson C, Adams M. Improving health literacy in patients with diabetes. Nursing. 2017:47(1):24-31. https://doi.org/10.1097/01.NURSE. 0000510739.60928.a9.

48. Williams MV, Davis T, Parker RM, Weiss BD. The role of health literacy in patient-physician communication. Fam Med. 2002;34(5):383-9.

49. Paasche-Orlow MK, Parker RM, Gazmararian JA, Nielsen-Bohlman LT, Rudd RR. The prevalence of limited health literacy. J Gen Intern Med. 2005;20(2): 175-84. https://doi.org/10.1111/j.1525-1497.2005.40245.x.

50. Fabbri M, Murad MH, Wennberg AM, Turcano P, Erwin PJ, Alahdab F, et al. Health literacy and outcomes among patients with heart failure a systematic review and Meta-analysis. JACC Heart Fail. 2020;8(6):451-60. https://doi.org/10.1016/j.jchf.2019.11.007.

\section{Publisher's Note}

Springer Nature remains neutral with regard to jurisdictional claims in published maps and institutional affiliations.

\section{Ready to submit your research? Choose BMC and benefit from:}

- fast, convenient online submission

- thorough peer review by experienced researchers in your field

- rapid publication on acceptance

- support for research data, including large and complex data types

- gold Open Access which fosters wider collaboration and increased citations

- maximum visibility for your research: over $100 \mathrm{M}$ website views per year

At BMC, research is always in progress.

Learn more biomedcentral.com/submissions 